\title{
UNMASKING FAKE NEWS AND PROPAGANDA IN THE HEALTHCARE SYSTEM: NURSES RESPONSIBILITY FOR PATIENTS' SAFETY
}

\author{
Asonye Christian Chinedu
}

\author{
School of Nursing, Babcock University, Ilisan Remo, Ogun State, Nigeria
}

Email: christianasonye1@gmail.com

Cite this article:

Asonye Christian Chinedu (2021), Unmasking Fake News and Propaganda in the Healthcare System: Nurses Responsibility for Patients' Safety. African Journal of Health, Nursing and Midwifery 4(4), 52-58. DOI: 10.52589/AJHNM-

Z4YHSGMG.

\section{Manuscript History}

Received: 8 June 2021

Accepted: 7 July 2021

Published: 20 July 2021

Copyright $\odot 2020$ The Author(s). This is an Open Access article distributed under the terms of Creative Commons AttributionNonCommercial-NoDerivatives 4.0 International (CC BY-NC-ND 4.0 ), which permits anyone to share, use, reproduce and redistribute in any medium, provided the original author and source are credited.
ABSTRACT: Nursing practice in the 21st century is faced with a barrage of fake news and propaganda that makes it critical for nurses to have the necessary skills to identify truth and discern bias in the healthcare system. The ability to respond critically to fake news and propaganda is more than a safe-guarding tool for nurses. However, it is also a crucial democratic competence in its own right. Analytical and critical thinking, knowledge, and critical understanding of the world, including the role of language and communication, lie at the heart of nursing. Therefore, the nurses' understanding of the nature and prevalence of propaganda, its seductions, aims, and consequences, and keeping critical thinking skills well-honed is vital in decreasing its influence in the healthcare settings and related harms, including lost opportunities to help patients.

KEYWORDS: Fake News, Propaganda, Nursing Practice, Healthcare System 
ISSN: 2689-9418

Volume 4, Issue 4, 2021 (pp. 52-58)

www.abjournals.org

\section{INTRODUCTION}

Fake news and propaganda are not new concepts but are as old as recorded history. However, recently these two concepts have become a subject of interests around the globe, especially as a result of the 2016 U.S, Presidential election (Tandoc, Lim \& Ling, 2018). These two concepts often overlap in meaning, but in reality, they are different. They are used to describe how the sharing of information causes harm intentionally or unintentionally - to control information flow, manage public opinion, or manipulate behaviour.

Furthermore, because of the explosion in information/communication and technology in recent times and the centrality of these factors in daily lives, healthcare consumers (patients and clients) are particularly vulnerable to propaganda and fake news. Healthcare consumers rely heavily on information circulated online for their knowledge of the health conditions and treatment modalities. However, to understand the nuance between fake news and propaganda, one may need to define each term and critically review these concepts.

Although there is no universal definition, fake news generally may refer to misleading content found on the internet, especially social media. Fake news may be defined as false news stories: the story itself is fabricated, with no verifiable facts, sources or quotes (Desai, Mooney \& Oehrli, 2017). Fake news exists within a broader ecosystem of mis-and disinformation. Misinformation is false or inaccurate information mistakenly or inadvertently generated or disseminated, and the intent is not to deceive. Disinformation is information that is deliberately created and spread to influence public opinion or obscure the truth.

Propaganda, on the other hand, is defined as "generally (connoting) the selective use of information for political effect" (National Endowment for Democracy (NED), 2017). More often than not, fake news does not meet the definition of propaganda. Its motives are usually financial, not political, and usually not tied to a larger agenda.

\section{Propaganda as Key in Quackery, Fraud, and Corruption in the Healthcare System}

Nurses live in a sea of propaganda pitches, including propaganda in the healthcare system healthcare professionals, big pharmaceutical industries, biotech companies, and the health insurance industry. Quackery entails the promotion and marketing of health products and procedures that have not been tested, and often unnecessary, and sometimes produces deleterious side effects by either healthcare professionals or others (Gambrill, 2010; 2012). Quackery often comes in several propaganda methods designed to influence beliefs and actions with the slightest thought possible in the healthcare system. Some of the indicators of quackery in the healthcare system include the promise of quick cures and sometimes the use of testimonials to support bogus claims of a particular product or procedure.

Clinical researchers are not left out of quackery, as they sometimes promote questionable conclusions (Vul, Harris, Winkielman, \& Pashler, 2009). These professionals trusted to guard the interests of the masses are sometimes propagandized by material prepared by public relations firms hired by pharmaceutical companies (Moynihan \& Cassels, 2005; Gambrill, 2010; 2012). Consumers are often bamboozled by these false claims in the various media about what is 
ISSN: 2689-9418

beneficial and what is not. Ioannidis (2005) argues that most published research findings are false. Indeed, it was partly because of bogus statements in texts, editorials, and professional articles that evidence-based practice (EBP) was developed.

Evidence-based practice (EBP) encompasses the conscientious and explicit problem-solving approach applied to clinical practice that incorporates available, current, valid and best evidence from well-designed research, patient values and preferences, and a clinician's expertise in making patient care decisions. Such an approach requires that the patient be involved as informed participants, whether this concerns a screening test for cancers or intervention for cancers or other disease conditions. The process and philosophy of EBP were designed to obliterate spurious claims by clinical researchers and involved all interested parties as informed consumers.

Typical propaganda ploys that threatened the consistent use of the evidence-based practice (EBP) in the healthcare system by researchers include the following: hiding limitations of research studies (Altman, 2002; Rubin \& Parrish, 2007); preparing uncritical, incomplete research reviews related to practice or policy; ignoring counterevidence to views promoted (e.g., Barkley et al., 2002); selective publication of research studies (e.g., Turner, Matthews, Linardatos, Tell, \& Rosenthal, 2008); ignoring well-argued alternative views and related evidence or misrepresenting them; transforming risks into diseases (e.g., osteoporosis); biased estimates of the prevalence of concerns; advocacy in place of evidence; arguing ad hominem (e.g., attacking the critic) rather than ad rem (responding to the argument). These propaganda ploys by researchers in healthcare professions result in inflated claims about "what we know" about causes, the accuracy of assessment measures, risks, and the effectiveness of remedies.

Fraud is the intentional misrepresentation of the effect of specific actions, such as taking a prescribed drug for a specific ailment, to persuade people to part with something of value, such as their money. It does this employing deception and misrepresentation, drawing on a variety of propaganda ploys, including the omission of relevant information such as harmful side effects (Gambrill, 2010; 2012). In the healthcare industry, the propaganda promoted by pharmaceutical companies has become so widespread, and conflicts of interests between academic/clinical researchers and such companies so huge. Most of the big drug companies have settled charges of fraud, off-label marketing, and other offences. However, the costs, while huge in some cases, are still overshadowed by the gains generated by these illegal activities and are therefore not much of a deterrent (Angell, 2009, p. 12).

Furthermore, corruption includes deceitful practices such as dumping unsafe drugs in third world countries and conflicts of interest that permeate medicine (Angell, 2008, 2009; Lo \& Field, 2009). It includes bribery of officials and kickbacks for referrals in the healthcare settings. According to Angell (2009), drug companies have given gifts worth tens of billions of dollars a year to some medical professionals (p. 8). This action has led the pharmaceutical industry to exercise significant control over how some medical professionals evaluate and use their products. This control and the conflicts of interest that permeate the enterprise tend to allow the industry-sponsored trials published in medical journals to consistently favour sponsors' drugsmainly because negative results are not published, positive results are repeatedly published in 
ISSN: 2689-9418

Volume 4, Issue 4, 2021 (pp. 52-58)

www.abjournals.org

slightly different forms, and a positive spin is put on even negative results (Turner et al., 2008; Angell, 2009, p. 10; Lo \& Field, 2009; Gambrill, 2010; 2012). Corruption in the health sector is real and vast that an international organization, Transparency International was created to decrease it (Busch, 2008).

\section{The Consequences of Propaganda}

The advertising and commercial search engine optimization techniques oftentimes promote search results to the top of the page from sources that only have economic interests rather than the most accurate and evidenced-based information (Beeken, Williams, Wardle, \& Croker, 2016; $\mathrm{Fu}$, Zook, Spoehr-Labutta, Hu, \& Joseph, 2016). This incorrect and misleading medical information portends grave danger to the health of patients. Fake news and propaganda affect individual patients both on a small scale and on a larger scale. Public health and health policy decisions may be based on misleading or incorrect information for political and economic gains rather than evidenced-based information (Speed, \& Mannion, 2017), affecting the patients in the long run. Health providers must also engage in critical and evidence-based evaluation of health information.

Other possible consequences of propaganda in the healthcare system may include failing to receive adequate services, creating bogus risks and alleged "diseases" and related worries, which tend to deprive patients of life pleasures. Other consequences may include increased dependency on specific healthcare professionals, thereby forcing patients to accept unneeded and perhaps harmful diagnostic tests and other interventions.

\section{Nurses' Responsibilities in Exposing Propaganda and Avoiding Its Influence}

Apart from providing care to patients with certain kinds of ill-health, the responsibilities of nurses in society include political, social, and economic functions and interests. The most important reason to be politically active is that politics is a means for nurses to advocate for patients. Advocacy is vital for nurses because social justice is a core value of the nursing profession. When nurses work in clinical settings, they can only help one patient at a time, and this work is central to our profession. But when nurses vote, sign a petition or participate in a political event, they can potentially help thousands of people at a time. The political activity takes the work of nurses from being a discreet event in one setting and raises it to a societal level. More so, that several social determinants of health can be impacted through political decisions. Nurses can help to protect health care access for vulnerable populations.

Nurses do more than just the art and act of caring for individuals requiring their services at the societal level. Nurses have always been at the forefront of changes in health care and public health issues. Nurses help advocate for health promotion, educate patients and the public on preventing illness and injury, providing care, assisting in the cure, participating in rehabilitation, and providing support. No other health care professionals have such a broad and far-reaching role. Nurses help families learn to become healthy by helping them understand the range of emotional, physical, mental and cultural experiences they encounter during health and illness. Nurses help people and their families cope with illness, deal with it, and, if necessary, live with it (or die peacefully) so that other parts of their lives can continue. 
ISSN: 2689-9418

Professional nursing practice today ranges from the provision of health services based on the latest evidence-based nursing research, in which patients are involved as informed participants. Therefore, the nurses' understanding of the nature and prevalence of propaganda, its seductions, aims, and consequences, and keeping critical thinking skills well-honed is vital in decreasing its influence in the healthcare professions and related harms, including lost opportunities to help patients. In addition, because propaganda is an essential part of the technological society that nurses live and work, it, therefore, means that nurses may not escape its influence. Nurses only recourse will be to understand how propaganda works, how it may influence their lives and duty, how it may influence the lives of their patients/clients, and how they may mute its effects.

To reduce the influence of fake news and propaganda, nurses will no doubt require varieties of tools and courage. Avoiding fake news and propaganda requires constant questioning of "is this true?" "What is the evidence?" The nurse requires courage, as he/she may be viewed as a troublemaker or a difficult person by colleagues, other healthcare professionals, and employer. The nurse sometimes may even get sued by a pharmaceutical company or be sacked. Nevertheless, the nurse must remain resolute, as his/her obligation is first to the patient.

Nurses must advocate and use evidence-based practice to weed out bogus claims, increase transparency regarding the uncertainty associated with making life-affecting decisions, and involves all parties as informed consumers in the delivery of healthcare services. Nurses can become aware of the power and pervasiveness of propaganda and develop fluency in recognizing indicators of propaganda and cultivating and using critical thinking to navigate through. Also, nurses need to create and maintain contacts with others, who value critical thinking, cultivate resistance to intimidation and blow the whistle on propaganda, fraud, and quackery in the healthcare system irrespective of persons involved. Furthermore, nurses should endeavour to read and accept primary sources of information (do not rely on secondary sources) and take advantage of valuable and trusted internet sources (such as Alliance for Human Research Protection (www.ahrp.org), www.criticalthinking.org, fallacyfiles.org, healthyskepticism.org,Innummercy.com, National Council Against Health Fraud).

Furthermore, nurses may use the Gricean maximums to decrease self-propaganda as well as to avoid propagandizing others (Grice, 1991; Ronald, 2006):

1. Maxim of Quantity: Quantity of Information. Make one's contribution as informative as is required (for the current purposes of the exchange). Do not make one's contribution more informative than is required.

2. Maxim of Quality: Be Truthful. Do not say what is believed to be false. Do not say that for which one lacks adequate evidence.

3. Maxim of Relation: Relevance. Be relevant (i.e., state things related to the current topic of the conversation).

4. Maxim of Manner: Be Clear. Avoid obscurity of expression, avoid ambiguity, be brief (avoid unnecessary prolixity/wordiness), be orderly. 
Nurses can keep in mind that in conversations where seeking the truth is the goal, efforts to avoid or block critical inquiry, so integral to propaganda, are never appropriate (Walton, 2008). Therefore, nurses can hone their critical thinking skills by virtue of their training and experience and become more aware of self-propaganda, such as the illusion of knowledge and certainty and related self-inflated assessments of their competence that foster uncritical acceptance of propaganda from external sources (Gambrill, 2010).

\section{SUMMARY AND CONCLUSION}

It is high time nurses pay more attention to propaganda in the healthcare system. An assessment of media sources and professional literature illustrates a continuing need for nurses to be vigilant about propaganda's pervasiveness and its effects, especially on patients' health. As propaganda methods have become more sophisticated, the influence of propaganda is more pervasive and more difficult to resist. Failure to educate nurses about the forms, aims, and consequences of propaganda in the healthcare system is a significant deficit in their education, resulting in avoidable harms to patients.

\section{Conflict of interest statement}

None declared.

\section{REFERENCES}

Altman, D., G. (2002). Poor-quality medical research: What can journals do? Journal of the 41American Medical Association, 287, 2765-2767.

Angell, M. (2008). Industry sponsored clinical research: A broken system. Journal of the American Medical Association, 300, 1069-1071.

Angell, M. (2009). Drug companies \& doctors: A story of corruption. New York Review of Books, $1 / 15$

Barkley, R. A., Cook, E. H., Diamond, A., Zametkin, A., Thapar, A., Teeter, A., et al. (2002). International Consensus Statement on ADHD. Clinical Child and Family Psychology Review, 5, 89-111.

Beeken, R. J., Williams, K., Wardle, J., \& Croker, H. (2016). “What about diet?” A qualitative study of cancer survivors' views on diet and cancer and their sources of information. European Journal of Cancer Care, 25(5), 774-783.

Busch, R. S., (2008). Healthcare fraud: Auditing and detection guide. Hoboken, NJ: John Wiley \& Sons Death sparks probe into China's Baidu. (2016, May 3). BBC News.

Eileen Gambrill (2010). Evidence-Informed Practice: Antidote to Propaganda in the Helping Professions? Research on Social Work Practice, 000(00), 1-19. doi:10.1177/1049731509347879 
Fake news advertisements promoted by Baidu, China's biggest search engine, may have contributed to the death of a 21-year-old student. Wei Zexi, who was diagnosed with a rare form of cancer, pursued an experimental treatment that was featured at the top of his search results.

Fu, L. Y., Zook, K., Spoehr-Labutta, Z., Hu, P., \& Joseph, J. G. (2016). Search Engine Ranking, Quality, and Content of Web Pages That Are Critical Versus Noncritical of Human Papillomavirus Vaccine. Journal of Adolescent Health, 58(1), 33-39. (U-M Library Access; PubMed Central)

Gambrill, E. D. (2012). Propaganda in the helping professions. New York: Oxford University Press. (U-M Library Access)

Ioannidis, J. P., A. (2005). Why most published research findings are false. PLoS Medicine, 2, e124.

Lo, B., \& Field, M. J. (Eds.). (2009). Conflict of interest in medial research, education and practice. Institute of Medicine. Washington, DC: National Academy Press

Moynihan, R., \& Cassels, A. (2005). Selling sickness: How the world's biggest pharmaceutical companies are turning us all into patients. New York: Nation Books

National Endowment for Democracy, (2017). DISTINGUISHING DISINFORMATION FROM PROPAGANDA, MISINFORMATION, AND "FAKE NEWS" retrieved from https://www.ned.org/issue-brief-distinguishing-disinformation-from-propagandamisinformation-and-fake-news/

Paul Grice (1991). Studies in the Way of Words. Cambridge, MA: Harvard University Press, pp. 78-79.

Rubin, A., \& Parrish, D. (2007). Problematic phrases in the conclusions of published outcome studies: Implications for evidence based practice. Research on Social Work Practice, 17, 592-602.

Shevon Desai, Hailey Mooney, \& Jo Angela Oehrli (2021). "Fake News," Lies and Propaganda: How to Sort Fact from Fiction. University of Michigan Library, Research Guides, retrieved from URL: https://guides.lib.umich.edu/fakenews

Speed, E., \& Mannion, R. (2017). The Rise of Post-truth Populism in Pluralist Liberal Democracies: Challenges for Health Policy. International Journal of Health Policy and Management, 6(5), 249-251. (U-M Library Access; PubMed Central)

Tandoc, E. C., Lim, Z. W., \& Ling, R. (2018). Defining "fake news": a typology of scholarly definitions. Digital Journalism 2018; 6: 137-153.

Turner, E. H., Matthews, A. M., Linardatos, E., Tell, R. A., \& Rosenthal, R. (2008). Selective publications of antidepressant trials and its influence on apparent efficacy. The New England Journal of Medicine, 358, 252-260.

Turner, E. H., Matthews, A. M., Linardatos, E., Tell, R. A., \& Rosenthal, R. (2008). Selective publications of antidepressant trials and its influence on apparent efficacy. The New England Journal of Medicine, 358, 252-260

Vul, E., Harris, C., Winkielman, P., \& Pashler, H. (2009). Puzzlingly high correlations in fMRI studies of emotion, personality and social cognition. Perspectives on Psychological Science, 4, 274-290.

Wardhaugh, Ronald. (2006). An Introduction to Sociolinguistics. Blackwell. 